\title{
Quantity and quality benefits of in-service invasive cleaning of trunk mains
}

\author{
Iftekhar Sunny $^{1}$, Stewart Husband ${ }^{1}$, Nick Drake ${ }^{2}$, Kevan Mckenzie ${ }^{2}$, and Joby Boxall ${ }^{1}$ \\ ${ }^{1}$ Pennine Water Group, Department of Civil and Structural Engineering, University of Sheffield, \\ S1 3JD, Sheffield, UK \\ ${ }^{2}$ Scottish Water, Juniper House, Heriot Watt Research Park, Edinburgh, \\ EH14 4AP, UK \\ Correspondence to: Iftekhar Sunny (izsunny1@sheffield.ac.uk)
}

Received: 24 January 2017 - Discussion started: 1 February 2017

Revised: 25 May 2017 - Accepted: 1 June 2017 - Published: 6 July 2017

\begin{abstract}
Trunk mains are high risk critical infrastructure where poor performance can impact on large numbers of customers. Both quantity (e.g. hydraulic capacity) and quality (e.g. discolouration) of trunk main performance are affected by asset deterioration in the form of particle accumulation at the pipe wall. Trunk main cleaning techniques are therefore desirable to remove such material. However, little is quantified regarding the efficacy of different maintenance interventions or longer-term changes following such cleaning. This paper presents an assessment of quantity and quality performance of a trunk main system pre, post and for 12 months following cleaning using pigging with ice slurry. Hydraulic calibration showed a 7 times roughness height reduction after ice slurry pigging, evidencing substantially improved hydraulic capacity and reduced headloss. Turbidity response due to carefully imposed shear stress increase remained significant after the cleaning intervention, showing that relatively loose material had not been fully removed from the pipe wall. Overall the results demonstrate that cleaning by pigging with ice slurry can be beneficial for quantity performance, but care and further assessment may be necessary to realise the full quality benefits.
\end{abstract}

\section{Introduction}

One of a water company's primary responsibilities is to operate and maintain their distribution network performance to ensure the continuous supply of safe, high water quality. As part of the drinking water network, transmission (trunk) mains are categorised as critical infrastructure as poor performance can impact large numbers of downstream customers. Due to strict operational and quality regulations and concern regarding potential consequences, UK water companies have tended to avoid operational activities associated with trunk mains (Husband and Boxall, 2015). However, this is becoming unavoidable and water utilities rehabilitation programmes now include large undertakings for the cleaning of large diameter mains (i.e. trunk mains) to manage asset resilience and reduce water quality risks. Considering the massive total expenditure allocated for cleaning interventions, in- frastructure performance assessment both for pre-post cleaning water quality and quantity are vital to justify the investment.

Quantity performance, e.g. hydraulic capacity and pipe roughness, can impact on the quantity of water received by the consumer, fire flow capacity and energy (pumping) costs. Continuous fouling, tubercles and scaling can increase hydraulic resistance and reduce effective pipe diameter (Boxall et al., 2004). Microbial activity on the pipe wall can also raise boundary resistance and affect hydraulic capacity (Cowle et al., 2014).

Discolouration is the water quality issue most apparent to the customer, causing the highest contact rates (i.e. number of contacts per 1000 population per year) worldwide. Particle size analysis demonstrated that discolouration processes are dominated by small particulate material $(2-25 \mu \mathrm{m})$; thus, their behaviour is unlikely to be dominated by gravity driven 

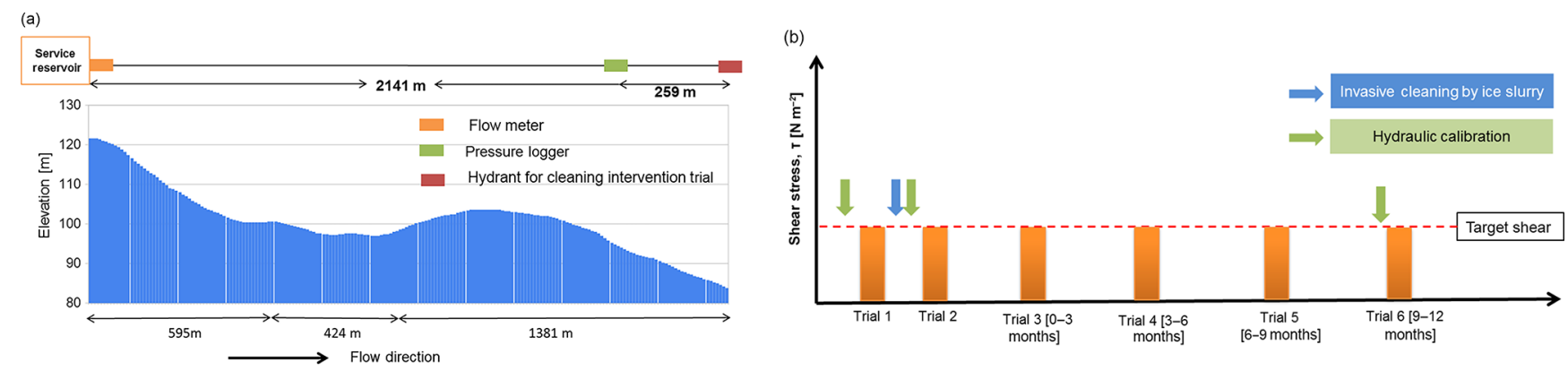

Figure 1. (a) Trunk main layout, monitoring points with elevation profile, and (b) cleaning intervention planning and timelines.

processes, but rather by continuously and ubiquitously attaching to the pipe wall by a complex combination of physical, chemical and biological processes (Boxall et al., 2001). The internationally validated PODDS (Prediction of Discolouration in Distribution Systems) model was developed and later verified that these particles are structured in stable cohesive layers and are released into the bulk water once an excess shear is imposed (Boxall and Saul, 2005). Recent studies have indicated that biofilms are a key component of the discolouration process. facilitating inorganic particle absorption within the organic matrix (Douterelo et al., 2014; Husband et al., 2016). PODDS concepts are well accepted for smaller diameter pipes in the distribution system and have started to be shown to be valid for large diameter transmission mains (Husband and Boxall, 2015).

As infrastructure ages, particulate material attached to the pipe wall can create a significant discolouration risk and reduce hydraulic capacity (Cook and Boxall, 2011; Shahzad and James, 2002). To remove accumulated material, water utilities often use invasive cleaning strategies as part of their rehabilitation programmes (AWWA, 2014). It is well established that invasive cleaning (e.g. ice pigging, air scouring, swabbing) can remove significant amounts of accumulated materials and biofilms from operational trunk mains (Ellison, 2003; Friedman et al., 2012). However, little is quantified regarding the efficacy of such interventions in terms of either quantity or quality improvement and how this changes over time following the intervention.

The aim of this paper is to investigate the quantity and quality performance benefits of an in-service trunk main invasive cleaning programme. Quantity performance of the selected trunk main was assessed through hydraulic modelling of monitored pre and post invasive cleaning flow and pressure data, with performance improvement evaluated by change in calibrated roughness height. Quality performance was assessed by monitoring, modelling and comparing the turbidity response due to controlled increase in hydraulic conditions pre and post intervention. Post cleaning evaluations were repeated over a 12-month period to explore longer-term performance changes.

\section{Methodology}

\subsection{Selected network characteristics}

The selected trial trunk main was $2.4 \mathrm{~km}$ of $228 \mathrm{~mm}$ internal diameter $(D)$ asbestos cement (AC) pipe. In this case, the trunk main was defined by an operation providing supply from a service reservoir into downstream distribution zones, with no consumers directly connected. The supplied DMAs (district metered areas) were mostly residential with consistent demand across the year with sub-daily variations. The downstream network had a demand driven diurnal daily flow pattern with an average downstream pressure of $42 \mathrm{~m}$ and a typical daily demand profile varying between 6 and $20 \mathrm{~L} \mathrm{~s}^{-1}$ $\left(0.14-0.48 \mathrm{~m} \mathrm{~s}^{-1}\right)$. The trunk main operates under gravity, with a low point in the long section as shown in Fig. 1a.

\subsection{Fieldwork procedure and monitoring}

The trunk main was built around 40 years ago. No known cleaning interventions have been implemented since it was commissioned. As part of a scheme to reduce discolouration customer contacts in the supplied DMAs and to remove particulate material and biofilm attached to the pipe wall, pigging with ice slurry was selected and implemented (Moore, 2013; Quarini, 2002). The method uses ice slurry to form a dynamic plug which increases shear on the pipe wall to dislodge built-up material. A site-specific amount of semisolid ice slurry was pumped through a UK standard washout hydrant at the trunk main inlet and emitted from a hydrant $2.4 \mathrm{~km}$ downstream. Before cleaning, the main was isolated from the supply to ensure no mixing of water into the supply with the semi-solid ice pig.

The trunk main served three separate downstream DMAs, with no connections over the $2.4 \mathrm{~km}$ length selected for cleaning. This layout ensures constant flow over the entire pipe length. Flow at the inlet, service reservoir level data and downstream pressure data allow for accurate hydraulic calibration and quantity performance. Pre and post pressure data were collected using Syrinix Transientminder loggers with 15 min resolution. Flow was monitored continuously at the 

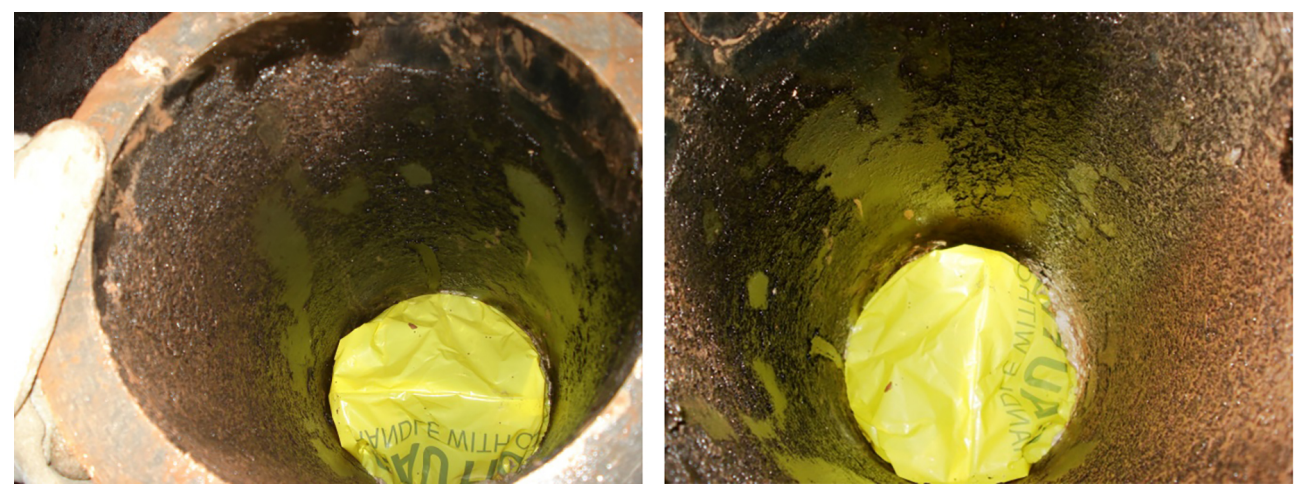

Figure 2. Pre-cleaning intervention pipe cut out.

service reservoir outlet using existing instrumentation, again at $15 \mathrm{~min}$ resolution.

Quality performance was assessed by imposing carefully managed flow increases and monitoring for any turbidity response; see Fig. 1b. From the PODDS concepts the imposed excess (above normal daily peak) shear stress would induce mobilisation of loose material associated with discolouration, with repeated operations of the same magnitude providing insight into any inter-period accumulation or other change in material layers. Managed increases in system shear stress were imposed through a hydrant standpipe. Flow increases were planned such that turbidity responses were expected to be well within regulatory limits (4 NTU at customers tap in the UK). These trials were executed before, to establish a base condition, and just after invasive cleaning to assess the amount of material left on the pipe wall, and quarterly thereafter to explore subsequent change. All flow conditioning trials were operated with repeatable conditions, i.e. similar time of day, duration, locations, equipment and section of trunk main to ensure the trial results were comparable. To monitor the downstream turbidity response, two ATI NephNet turbidity loggers were used with a $1 \mathrm{~s}$ sampling interval. The ATI turbidity loggers were calibrated under laboratory conditions and two loggers used to provide dual validation. Spot checks against a HACH handheld turbidity instrument, calibrated against formazin turbidity standards, were also undertaken. A specially designed ABB flow meter attached to a UK standard hydrant standpipe from Langham industrial controls was used to measure flow (and therefore shear stress) with local manual control of a gate valve.

\section{Results and discussions}

\subsection{Pipe cut out}

A pre-intervention pipe cut out was taken from the trunk mains low point (see Fig. 1a) to assess the pipe's internal condition and amount of accumulated material present on the asbestos cement pipe wall which is shown in Fig. 2. From the visual assessment, accumulated material can clearly be seen around the full pipe circumference, supporting the PODDS model concepts. The cut out was taken at the longitudinal low point, such that all gravitationally driven self-weight settling processes that would have led to invert deposits were explored, with none being found.

\subsection{Hydraulic capacity assessment}

Hydraulic models were developed and simulated in standard EPANET software (Rossman, 2000). The hydraulic model was calibrated using monitored flow as an input and then by minimising visual dissimilarities and maximising the correlation coefficient $\left(R^{2}\right)$ between downstream simulated and measured pressure. While pipe roughness $\left(k_{s}\right)$ alone can produce an accurate simulation of observed pressure, inaccurate representation of velocities which can be significant for the quality application can persist. This is because hydraulic calibration is an indeterminate problem space where various combinations of diameter and roughness can produce similar headloss and hence downstream pressure. Calibration optimisation processes should also consider changing pipe internal diameter, particularly for large roughness heights (Boxall et al., 2004). During the model construction, minor losses were incorporated as EPANET loss coefficient inputs, determined from the EPANET manual (Rossman, 2000). However, these values were not considered as calibration variables and were fixed throughout the simulations, so effects would have been constant. The trunk main studied had no known leakage, as assessed through night line analysis. The effect of any unknown background leakage would have been manifest in the flow data that was used as an input to the model. The night line was not observed to change from the start to the end of the monitoring period (other than due to known operational changes), suggesting that no new leakage occurred during the study. The estimated boundary condition of pipe roughness and the diameter using the Boxall et al. (2004) concept has been applied to the Parameter ESTimator (PEST) (Doherty, 2005; Méndez et al., 2013) in conjunction with the EPANET model to determine the best possible solutions comparing simulated and measured down- 

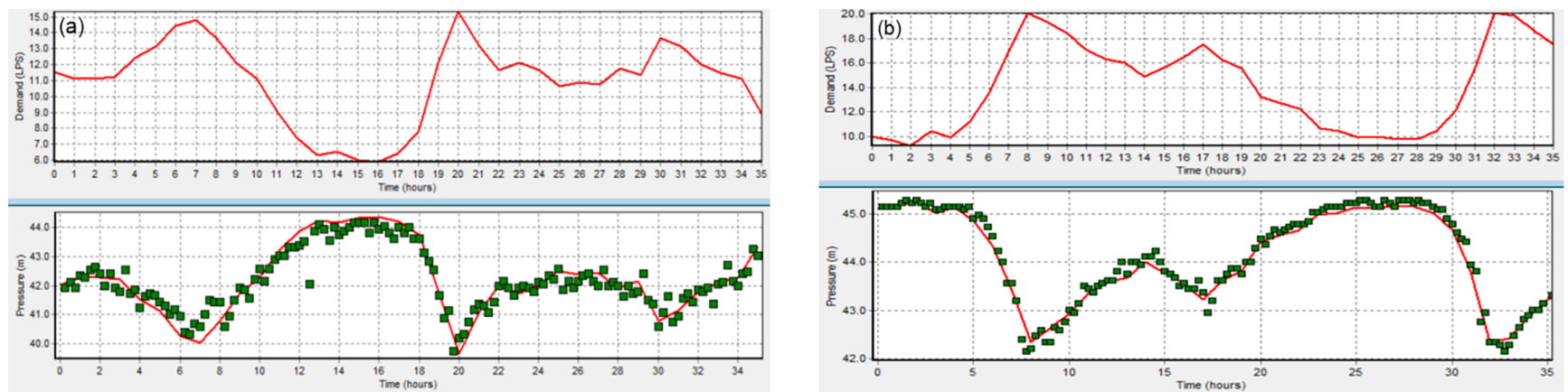

Figure 3. Pre and post invasive cleaning hydraulic simulation in EPANET. Demand in $\mathrm{Ls}^{-1}$ (top graphs) and simulated and measured pressure head in $\mathrm{m}$ (bottom graphs). (a) Pre cleaning; (b) post cleaning.

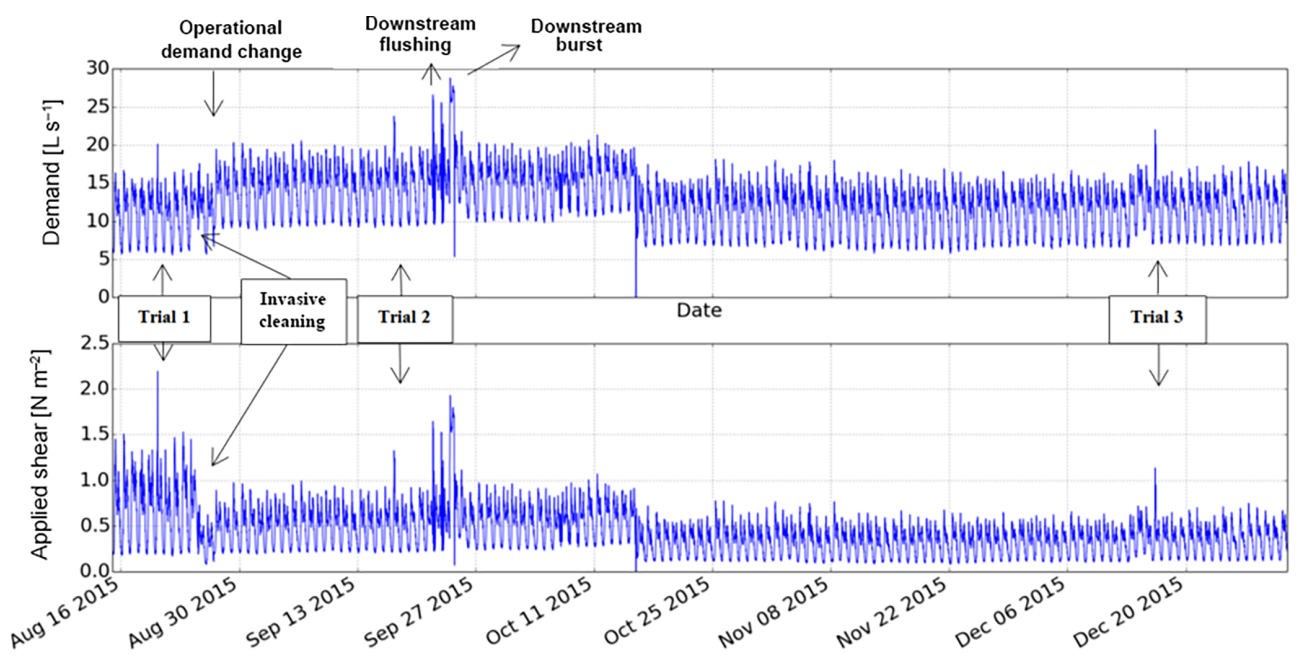

Figure 4. Daily demand in $\mathrm{Ls}^{-1}$ and applied shear stress in $\mathrm{N} \mathrm{m}^{-2}$ variations from August 2015 till December 2015.

stream pressure. The optimised paired value (roughness and diameter) solution was constrained by the original pipe diameter of $228 \mathrm{~mm}$. Figure $3 \mathrm{a}$ shows the flow and simulated and measured pressure data for pre-invasive cleaning. As the main is around 40-year old AC, it was expected that it might have relatively high roughness due to continuous material fouling. From the optimisation, the best achievable result for pre-invasive cleaning trial was $6.8 \mathrm{~mm}$ pipe roughness and $215.0 \mathrm{~mm}$ effective diameter.

After the ice slurry cleaning process, a similar monitoring programme was conducted. With the new monitored pressure and flow data, the hydraulic model was re-optimised (Fig. 3b), with the best model fit achieved with a pipe roughness of $1.0 \mathrm{~mm}$ and an effective diameter of $227.4 \mathrm{~mm}$. Thus, from hydraulic model optimisation, a 7 times reduction in roughness height was found after the invasive cleaning. This demonstrates improved mains carrying capacity and indicates that the ice slurry intervention removed material layers that cause significant hydraulic losses.

A similar pressure and flow monitoring programme was conducted 12 months after the invasive cleaning to quan- tify any further change in hydraulic capacity. Unfortunately, practical constraints were such that the data necessary for detailed hydraulic calibration were not collected for all events. The calibrated roughness was after 12 months found to increase to $2.3 \mathrm{~mm}$ and effective diameter reduced to $224 \mathrm{~mm}$. This suggests longer-term accumulation and continuous particulate fouling that impact on the hydraulic capacity. A correlation between change in roughness and turbidity response potentially indicates the growth of material on the pipe wall over time; however, previous work (Boxall et al., 2003a) has suggested that site-specific change in roughness $(\sim 0.01 \mathrm{~mm})$ corresponding to notable turbidity ( $\sim 10 \mathrm{NTU})$ response is significantly less than the accuracy of the hydraulic calibration possible here. Table 1 presents all the diameters and roughness values.

\subsection{Water quality assessment}

Water quality performance was assessed by measuring the discolouration response due to imposed excess shear stress, repeated as set out in Fig. 1b. Figure 4 presents daily demand 
Table 1. Hydraulic parameter optimisation results for pre, post and 12 months after invasive cleaning.

\begin{tabular}{lrrrr}
\hline $\begin{array}{l}\text { Hydraulic parameters } \\
\text { and calibration } \\
\text { efficiency }\end{array}$ & $\begin{array}{r}\text { Initial } \\
\text { mean } \\
\text { diameter }\end{array}$ & $\begin{array}{r}\text { Pre invasive } \\
\text { cleaning } \\
\text { (optimised) }\end{array}$ & $\begin{array}{r}\text { Post invasive } \\
\text { cleaning } \\
\text { (optimised) }\end{array}$ & $\begin{array}{r}+12 \text { months post } \\
\text { invasive cleaning } \\
\text { (optimised) }\end{array}$ \\
\hline$k_{S}(\mathrm{~mm})$ & - & 6.8 & 1.0 & 2.3 \\
Diameter $(\mathrm{mm})$ & 228.0 & 215.0 & 227.4 & 224.0 \\
$R^{2}(-)$ & - & 0.9424 & 0.9681 & 0.9227 \\
\hline
\end{tabular}
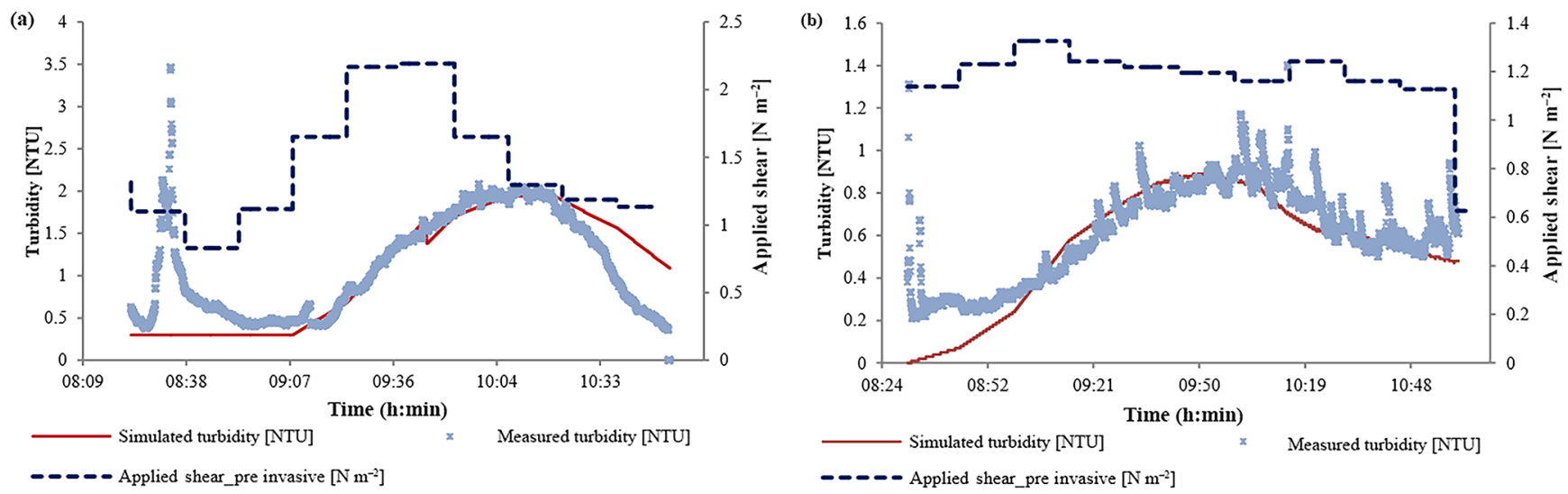

Figure 5. Measured and simulated turbidity response (a) before the invasive cleaning trial and (b) after the invasive cleaning trial.

and applied shear stress during the first, second and third of these increases in flow (hence the change in shear stress) and the ice slurry pigging. Typical maximum daily shear stress before the cleaning intervention was about $1.5 \mathrm{~N} \mathrm{~m}^{-2}$, estimated using calibrated roughness values. Due to operational circumstances, daily peak demand had increased after the intervention for more than a month and, as a result, daily shear stress was also altered. From 27 August 2015 till 16 October 2015 , new properties were connected to the downstream distribution zone fed from this trunk main due to repair work in a neighbouring zone. About $3 \mathrm{~L} \mathrm{~s}^{-1}$ demand was increased and transported to the downstream reservoir during this process, which can be confirmed from the constant nightline profile for over 2 months. Revised maximum daily shear stress after invasive cleaning intervention calculated from an improved $k_{s}$ value was $1.0 \mathrm{~N} \mathrm{~m}^{-2}$, and later it was changed to $0.6 \mathrm{~N} \mathrm{~m}^{-2}$. This value persisted throughout the following 12 months of monitoring. A planned nighttime downstream network flushing was undertaken from 22 September till 23 September (2 nights). Also, there was a downstream burst event recorded as starting on 24 September and continuing until 25 September (Fig. 4). Unfortunately, there were no turbidity loggers deployed on this trunk main which could have captured the continuous mobilisation response due to the burst event. These events could have mobilised accumulated material as it was higher than the trial 2 event and potentially influence trial 3 responses.
Figure 5a shows the measured and simulated turbidity response due to shear stress increases before the ice slurry pigging intervention. It is evident from Fig. 5a that material started to mobilise during the shear step of 1.1 to $1.65 \mathrm{~N} \mathrm{~m}^{-2}$, consistent with a normal daily max shear stress of $1.5 \mathrm{~N} \mathrm{~m}^{-2}$. Maximum shear stress during the trial was $2.20 \mathrm{~N} \mathrm{~m}^{-2}$, generating a measured peak turbidity of about 2.0 NTU. To avoid the regulatory turbidity limit (4.0 NTU), shear stress was reduced stepwise to $1.13 \mathrm{~N} \mathrm{~m}^{-2}$, and it continued until the turbidity response had returned to pre-trial levels. An initial turbidity spike was observed around 08:30 due to the connection and opening of the hydrant.

To assess the discolouration risk from the main after it had been invasively cleaned, a similar trial was conducted 3 weeks after the pigging intervention (see trial timeline in Fig. 1b). Figure 5b shows that despite the cleaning, material was mobilised from the pipe wall by only a small increase in excess shear stress. The maximum operated shear stress during the second trial was $1.32 \mathrm{~N} \mathrm{~m}^{-2}$ and peak turbidity was about 1.0 NTU. As with other case studies, the ice slurry pigging was shown to remove significant amounts of materials. However, these results show that loose material was present in the pipeline only 3 weeks after the invasive cleaning.

Previous research has suggested that ice plug pressure or friction forces can drop as the trial continues (Candy et al., 2010; Shire, 2006). Therefore, potentially the cleaning performance was inadequate for removing all the materials during ice plug formation and movement along the pipe length. 
Table 2. Test parameters for material release rate calculations.

\begin{tabular}{lcrrrrrr}
\hline Parameters & Unit & Trial 1 & Trial 2 & Trial 3 & Trial 4 & Trial 5 & Trial 6 \\
\hline Diameter $(D)$ & $\mathrm{mm}$ & 215.0 & 227.4 & 227.4 & 227.4 & 227.4 & 224.0 \\
Pipe roughness $\left(k_{S}\right)$ & $\mathrm{mm}$ & 6.8 & 1.0 & 1.0 & 1.0 & 1.0 & 2.3 \\
\hline
\end{tabular}
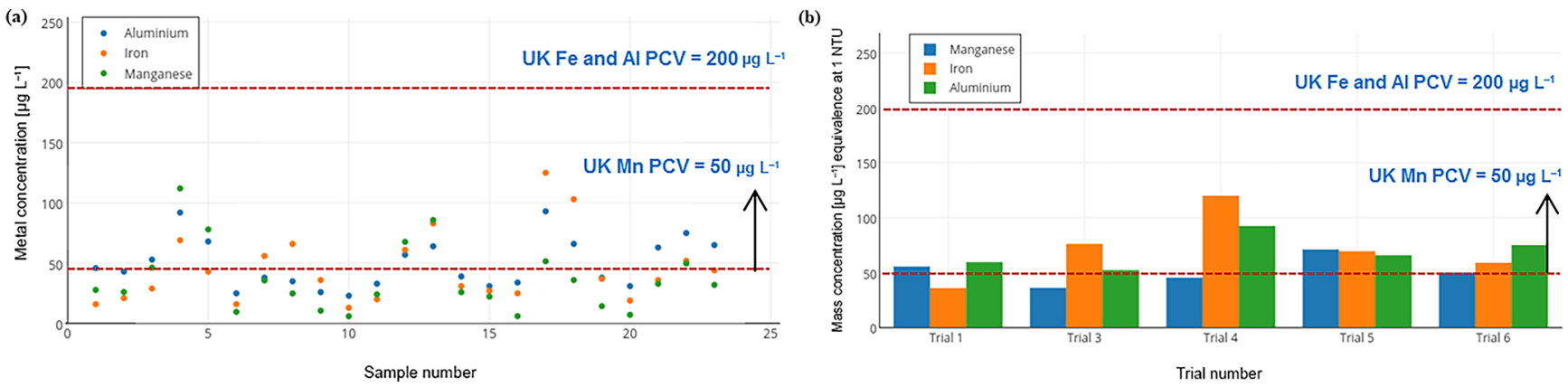

Figure 6. (a) All metal sampling during trial durations; (b) metal concentration equivalence at 1.0 NTU.

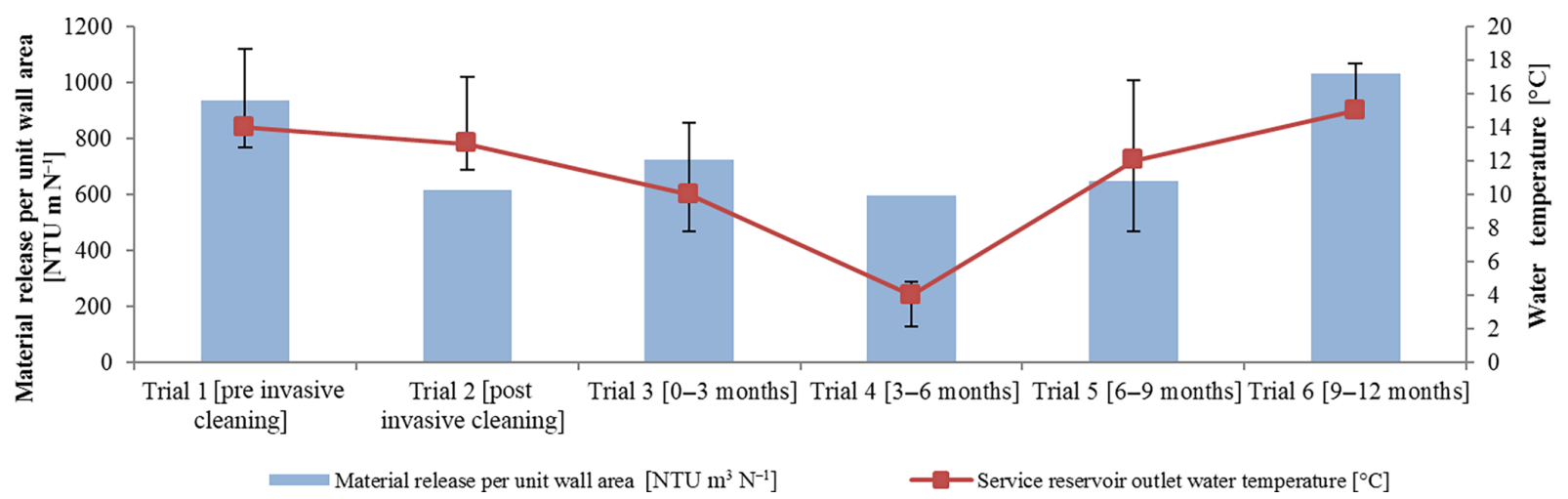

Figure 7. Volumetric turbidity output accounting for excess imposed shear during shear stress trials with service reservoir outlet mean temperature.

As noted previously, the trial main had a low point in its longitudinal profile, as shown in Fig. 1a. Contractors for the invasive cleaning programme suggested the ice plug may have dropped pressure while flowing upwards from the dip section, possibly leaving material there. However, Fig. 5b shows a linear increase in turbidity and hence mobilisation of material from over the full pipe length with no spike in turbidity associated with the travel time from the trunk main low point.

Results of metal samples during the trials are shown in Fig. 6, except for trial 2, as samples could not be collected during the trial durations. Figure 6 a shows that the concentration of manganese (Mn) was high and occasionally exceeding the UK regulatory prescribed concentration value (PCV) of $50 \mu \mathrm{g} \mathrm{L}^{-1}$. Iron and aluminium concentrations are also shown to be significant although well below the UK PCV limit. Figure $6 \mathrm{~b}$ presents the results for calculated metal concentrations for an equivalent 1.0 NTU limit. Manganese PCV is likely to be exceeded during all trials at this threshold, sug- gesting high manganese content in the bulk water. From this it could be suggested that the accumulation or fouling effects are driven by manganese and other metal (e.g. iron and aluminium) precipitation from the bulk water, which is consistent with previous research findings (Boxall et al., 2003b; Husband and Boxall, 2011; Seth et al., 2004). However, a complete conclusion about the inorganic particles responsible for the observed discolouration cannot be drawn from this sampling study alone as undisturbed sampling data from the trunk main were unavailable. Also, the previous work has indicated that biological processes impact on material accumulation and hence influence discolouration risks (Gauthier et al., 1999; Husband et al., 2016).

As can be seen from Fig. 5, the PODDS model simulated successfully both pre and post shear stress trial induced turbidity responses. However, the invasive cleaning changed the accumulated layer conditions from pre to post in such a way that it is not possible to compare the modelling results with- 
out a continuous mobilisation-accumulation tracking facility which the PODDS model cannot facilitate. It is possible to simulate the discolouration response for a set of flow (or shear stress) increases from trials 3 to 6 taking information from Fig. 5b model parameters; however, due to the limited continuous flow and turbidity data, comparisons made here are only with fieldwork results. Flow increases and subsequent material mobilisation were repeated at 3-monthly intervals to assess the ongoing accumulation of loose material. Due to operational constraints, the imposed shear stresses were not exactly the same, as in Fig. 4. Hence results are not directly comparable. In order to aid comparison, the time series data was converted to "volumetric turbidity" due to imposed shear increase to estimate the material release rate per unit wall area. This was calculated by integration of the time turbidity plots with respect to the amount (flow rate with time) of water used and divided by the maximum imposed shear stress and pipe internal wall area. This effectively accounts for differences in mass flux but assumes mobilisation is linear with flow rate. While the last assumption is not valid, it is an acceptable simplification over the range of different excess shear stresses imposed here. Table 2 presents the test parameters used to calculate the material release rate for all trials. Though the roughness and diameter values were unknown in trials 3, 4 and 5, paired parameter values were assumed to be equal to trial 2. To calculate imposed excess shear stress addition to Table 2, discolouration material density $(\rho)$ and gravity were used at $1100 \mathrm{~kg} \mathrm{~m}^{-3}$ (Boxall et al., 2001; Ryan et al., 2008) and $9.81 \mathrm{~m} \mathrm{~s}^{-2}$.

Figure 7 summarises these amounts of volumetric turbidity mobilised from all trials, together with indicative service reservoir outlet seasonal water temperature collected by spot samples as part of the regular sampling programme. As expected, the pre-invasive cleaning trial generated a relatively higher turbidity response compared to post cleaning trials. However, the 3-week post invasive cleaning amount was high as well, suggesting that the material was able to regenerate quicker after invasive cleaning compared to the conditioning trials, rapidly developing to re-establish equilibrium between cohesive layer forces and daily peak shear stress, or that material loosened by the slurry was not fully removed. While the invasive cleaning was effective in removing a significant amount of historical accumulations, the remaining loose particles were not necessarily mobilised easily through ice slurry, and hence represent discolouration risks. After 12 months this weaker material risk had returned, but the stronger material apparently responsible for the initial roughness height had not. The following 3-month period, where temperature was lowest, shows the least amount of material accumulated and subsequently mobilised by the controlled flow increase, while the final 3-month period where temperature was greatest showed the overall highest levels of mobilisation of weakly adhered material. Hence this indicates a temperature influence on material regeneration process in this trunk main. Previous research evidence has also sug- gested a temperature impact on material regeneration and discolouration processes, and this is potentially associated with microbial activity (Blokker and Schaap, 2015; Sharpe, 2012). However, as a single trunk main study it is not possible to confirm temperature and pipe material influence on biofilms and hence significance of discolouration risks without investigating similar test profiles on varying pipe materials.

\section{Conclusions}

The study investigates pre, post and long-term, quality and quantity performance of a trunk main subject to invasive cleaning by ice slurry pigging. Benefits expected due to invasive cleaning included an improvement in hydraulic capacity and a reduction in discolouration risk. The findings from the fieldwork are summarised below.

- Hydraulic modelling and calibration showed pipe roughness reduced by about 7 times after semi-solid ice slurry cleaning intervention. However, monitoring and modelling after 12 months showed that the roughness had slowly increased after the intervention, suggesting continuous material fouling impacting on the hydraulic capacity.

- Pipe wall material mobilisation through controlled shear stress increases removed significant material after the selected invasive cleaning process. This indicates that loose particles remained on the pipe wall and that there was still a risk of discolouration after this invasive cleaning intervention was performed.

- Repeated flow conditioning trials showed ongoing material accumulation, evidence of ongoing endemic processes.

Data availability. For contractual reasons, data are not being published online publicly. However, the authors would welcome any comment or queries from other readers.

Competing interests. The authors declare that they have no conflict of interest.

Acknowledgements. The author gratefully thanks Scottish Water for site access and data provision to complete this research work. The research work is funded by Scottish Water and the Pennine Water Group, EPSRC platform grant EP/1029346/1.

Edited by: Edo Abraham

Reviewed by: Mirjam Blokker, Thomas Walski, and one anonymous referee 


\section{References}

AWWA: M28 Rehabilitation of Water Mains, 3rd Edn., American Water Works Association, 132 pp., 2014.

Boxall, J. and Saul, A.: Modelling Discoloration in Potable Water Distribution Systems, J. Environ. Eng., 131, 716-725, https://doi.org/10.1061/(ASCE)0733-9372(2005)131:5(716), 2005.

Boxall, J., Skipworth, P. J., and Saul, A.: A novel approach to modelling sediment movement in distribution mains based on particle characteristics, in: Water Software Systems: V. 1: Theory and Applications (Water Engineering \& Management), Hertfordshire, UK, 263-273, 2001.

Boxall, J., Saul, A., Gunstead, J. D., and Dewis, N.: Regeneration of Discolouration in Distribution Systems, World Water \& Environmental Resources Congress 2003, Philadelphia, Pennsylvania, United States, 1-9, 2003a.

Boxall, J., Skipworth, P. J., and Saul, A. J.: Aggressive flushing for discolouration event mitigation in water distribution networks, Wa. Sci. Technol., 3, 179-186, 2003b.

Boxall, J. B., Saul, A. J., and Skipworth, P. J.: Modeling for Hydraulic Capacity, J. Am. Water Works Ass., 96, 161-169, 2004.

Blokker, E. J. M. and Schaap, P. G.: Temperature Influences Discolouration risk, in: Computing and Control for the Water Industry Procedia Engineering, UK, 280-289, 2015.

Candy, H., Quarini, G. L., Heskins, N., Ainslie, E., Herbert, M., Deans, T., and Ash, D.: Ice pigging technology to clean potable water trunk mains in an environmental friendly and cost effective manner, IWA World Water Congress and Exhibition, IWA Publishing, Montreal, Canada, 19-24 September 2010.

Cook, D. and Boxall, J.: Discoloration Material Accumulation in Water Distribution Systems, Journal of Pipeline Systems Engineering and Practice, 2, 113-122, https://doi.org/10.1061/(ASCE)PS.1949-1204.0000083, 2011.

Cowle, M. W., Babatunde, A. O., Rauen, W. B., BockelmannEvans, B. N., and Barton, A. F.: Biofilm development in water distribution and drainage systems: dynamics and implications for hydraulic efficiency, Environmental Technology Reviews, 3, 3147, https://doi.org/10.1080/09593330.2014.923517, 2014.

Doherty, J.: "PEST - Model-Independent Parameter Estimation" User Manual, Watermark Numerical Computing, Brisbane, Australia, 2005.

Douterelo, I., Husband, S., and Boxall, J. B.: The bacteriological composition of biomass recovered by flushing an operational drinking water distribution system, Water Res., 54, 100-114, https://doi.org/10.1016/j.watres.2014.01.049, 2014.

Ellison, D.: Investigation of Pipe Cleaning Methods, Awwa Research Foundation, Denver USA, 142 pp., 2003.
Friedman, M., Lakin, B., and Moore, R.: Best Practice Cleaning Mains: Clean, Pig, or Dig?, Opflow, 38, 10-13, https://doi.org/10.5991/OPF.2012.38.0044, 2012.

Gauthier, V., Gérard, B., Portal, J.-M., Block, J.-C., and Gatel, D.: Organic matter as loose deposits in a drinking water distribution system, Water Res., 33, 1014-1026, https://doi.org/10.1016/S0043-1354(98)00300-5, 1999.

Husband, P. S. and Boxall, J. B.: Asset deterioration and discolouration in water distribution systems, Water Res., 45, 113-124, https://doi.org/10.1016/j.watres.2010.08.021, 2011.

Husband, S. and Boxall, J.: Predictive water quality modelling and resilience flow conditioning to manage discolouration risk in operational trunk mains, J. Water Supply Res. T., 64, 529-542, https://doi.org/10.2166/aqua.2014.042, 2015.

Husband, S., Fish, K. E., Douterelo, I., and Boxall, J.: Linking discolouration modelling and biofilm behaviour within drinking water distribution systems, Water Sci. Technol., 16, 942-950, https://doi.org/10.2166/ws.2016.045, 2016.

Méndez, M., Araya, J. A., and Sánchez, L. D.: Automated parameter optimization of a water distribution system, J. Hydroinform. 15, 71-85, https://doi.org/10.2166/hydro.2012.028, 2013.

Moore, R.: Ice Pigging Offers Sustainable Main Cleaning Technology, Opflow, 39, 14-16, https://doi.org/10.5991/OPF.2013.39.0013, 2013.

Quarini, J.: Ice-pigging to reduce and remove fouling and to achieve clean-in-place, Appl. Therm. Eng., 22, 747-753, https://doi.org/10.1016/S1359-4311(02)00019-4, 2002.

Seth, A., Bachmann, R., Boxall, J., Saul, A., and Edyvean, R.: Characterisation of materials causing discolouration in potable water systems, Water Sci. Technol., 49, 27-32, 2004.

Shire, G. S. F.: The behaviour of ice pigging slurries, Thesis, University of Bristol, Bristol, 2006.

Sharpe, R.: Laboratory investigations into processes causing discoloured potable water, Thesis, University of Sheffield, Sheffield, 2012.

Rossman, L.: Epanet 2: User Manual (User Manual No. EPA/600/R00/057), USEPA, Cincinnati, OH, 2000.

Ryan, G., Mathes, P., Haylock, G., Jayaratne, A., Wu, J., NouiMehidi, N., Grainger, C., and Nguyen, B. V.: Particles in Water Distribution System: Characteristics of particulates Matter in Drinking Water Supplies, CRC, Australia, 2008.

Shahzad, A. and James, W.: Loss in Carrying Capacity of Water Mains due to Encrustation and Biofouling, and Application to Walkerton, Ontario, Journal of Water Management Modeling, R208-19, 303-323, https://doi.org/10.14796/JWMM.R20819, 2002. 